\title{
Rational voters in a partisanship model
}

\author{
Otto H. Swank \\ Erasmus University Rotterdam, TRACE, OCFEB, P.O. Box 1738, \\ NL-3000 DR Rotterdam, The Netherlands
}

Received: 15 February 1993/Accepted: 29 March 1994

\begin{abstract}
This paper examines a voter model for the US which is interconnected with the partisan theory. In our model, voters are rational and forward-looking. They are perfectly informed about the preferences of political parties and about the state of the economy. The predictions of our voter model differ from the predictions of conventional voter models, according to which the incumbent benefits from low unemployment and low inflation, irrespective of its political colour. In a partisan setting, the democratic party benefits from high unemployment and the republican party benefits from high inflation. Regressions of presidential approval rates indicate that the predictions of both the partisan voter model and the conventional model are consistent with the data.
\end{abstract}

\section{Introduction}

Numerous studies indicate that macroeconomics and politics are interrelated. In the political literature, the retrospective voter model has acquired a stable position. In this model, voters evaluate political parties on the basis of their past performances. The basic idea behind this model is that voters reward the incumbent party in good times and punish it in bad times. Considerable evidence exists that shows that incumbent parties benefit from favourable macroeconomic conditions, such as low unemployment and low inflation (Kramer 1971; Fair 1978; Frey and Schneider 1978; Fiorina, 1981).

As to politics in macroeconomic models, two strands of research can be distinguished. The first originated with Nordhaus (1975), who suggested that administrations generate cycles in economic variables, called political business cycles, in order to increase their chances of reelection. Political business cycle models and retrospective voter models are closely interconnected. Given that voters are retrospective and that administrations aim at reelection, administrations will try to accomplish favourable economic conditions immediately before elections. Nowadays, political business cycle models as developed by Nordhaus are generally viewed with scepticism. Doubts have risen about the ability of policy 
makers to generate cycles in real variables, such as unemployment. Moreover, little evidence exists that supports the predictions of the Nordhaus model (see McCallum 1978).

The second strand of research started with Hibbs (1977), who showed that unemployment tended to decline during democratic administrations and tended to rise during republican administrations. These findings suggested the existence of polarised preferences. Like Nordhaus' model, Hibbs' model was based on an exploitable Phillips curve. However, Alesina and Sachs (1988) showed that polarised preferences may still give rise to partisan cycles in models with rational expectations, due to electoral surprises. The predictions of this rational partisan model differs from the Hibbs model in that real partisan effects are concentrated in the first part of each administration's term. There exists considerable evidence in favour of the (rational) partisan theory. Alesina (1987), Beck (1982), Chappell and Keech (1988) and Swank (1992) confirm Hibbs' findings that unemployment rates are lower under democratic administrations than under republican administrations.

In conventional retrospective voter models, partisan behaviour of political parties is often ignored. Against the background of the existing evidence for partisan cycles in economic variables, this should be regarded as a principal shortcoming of these models. In a partisan framework, elections have important economic consequences. Rational voters will take these effects into consideration in making their vote decisions. This does not necessarily imply, however, that the key idea behind the retrospective voter models that the incumbent party benefits from favourable economic outcomes is false. Apart from their preferences, political parties may differ in their abilities to achieve economic goals. Favourable economic outcomes may indicate that the incumbent party is particularly able to deal with current economic problems.

In this paper, we examine a voter model for the US which is interconnected with the partisan theory. Political parties differ in their preferences over unemployment and inflation as in Alesina (1987). The working of the economy is described by a simple unemployment equation due to Blanchard and Summers (1986) which relates unemployment to lagged unemployment and the difference between expected and realised inflation. Policy makers may try to reduce unemployment by generating inflation surprises. With respect to economic outcomes, our model has the same implications as does the model of Alesina (1987). Unemployment tends to decline during democratic administrations and to increase during republican administrations. In contrast to the Alesina model, these effects are partially lasting due to the lagged unemployment term in the unemployment equation. Swank and Hebbink (1992) show that the predictions of this model are consistent with post-war US data. In our model, voters are rational and forward-looking. They are perfectly informed about the preferences of political parties and about the state of the economy which changes over time due to lagged effects in the economy. Voters cast their ballots for the party that, if elected, will maximise their utility. The predictions of the voter model differ from the predictions of the conventional retrospective voter model. We show that the democratic party benefits from high unemployment and suffers from high inflation. It appears that voters use their votes to choose the party that best fits the economic situation.

This paper builds on recent studies by Alesina (1988), Chappell and Keech (1989) and Rogoff and Sibert (1988). In these studies, voters are assumed to know and understand the economic constraints policy makers face. In this respect, this study deviates from the earlier literature on voter behaviour (Kramer 1971; Fair 
1978), in which voters just punish administrations for poor economic performance, without understanding the relationships between variables. Furthermore, this paper deviates from the existing literature in that it emphasizes the effects of partisan motives on voter behaviour. In the existing literature, voters punish administrations for undesirable economic outcomes. In this paper a voter model is discussed in which undesirable outcomes may increase the popularity of the administration in office.

The paper is organised as follows. In the next section, the economic problems facing policy makers are described. We show how electoral uncertainty and lagged effects in the economy affect the trade-off between unemployment and inflation. Shifts of the Phillips curve play an important role in Sect. 3, where we examine two voter models, the retrospective voter model and the partisan voter model, and show how these models are related to the government model discussed in Sect. 2. In Sect. 4, we present some simple regressions of approval rates for American presidents, indicating that the predictions of both voter models are consistent with the data.

\section{A small economic model}

In this section, we consider a simple model of the labour market, due to Blanchard and Summers (1986) and a politico-economic model, due to Alesina (1987). From the Blanchard-Summers model, an unemployment equation will be derived that relates unemployment to unemployment last period and the difference between realised and expected inflation. In the politico-economic model the behaviour of the private sector will be described by this equation.

As in earlier politico-economic models, the outcomes of our model heavily rely on the assumptions about the timing of policy relative to private actions. At the end of each period, nominal wage contracts are signed which last one period. These contracts are assumed to be non-contingent on the state of the world. Thus short-run nominal rigidities exist and the policy maker is able to create inflation surprises. Following Alesina (1987), we distinguish electoral and non-electoral periods. Elections are held at the beginning of each electoral period. Immediately after the elections, the winning party takes office. In a partisan framework, elections create uncertainty about future policies. The economy is assumed to be composed of small separate markets, so that firms and (firm specific) unions ignore the effects of their actions on economic policy and election outcomes. This implies that election outcomes are exogenous from the private agents' point of view. The probability distribution of election outcomes is assumed to be known: party $d$ is elected with probability $\pi$ and party $r$ with probability $(1-\pi){ }^{1}$ In post-electoral periods, the identity of the policy maker is known and so no uncertainty exists about future policies.

To facilitate the analysis we will make some simplifying assumptions. First, we assume that all agents care only about current economic outcomes. Put differently, we restrict the analysis to a one-shot game. Admittedly, this assumption reduces the scope of this paper, since it prevents us from analyzing important issues, such as reputation and signalling. Second, following Hibbs (1977), Alesina (1987) and

\footnotetext{
${ }^{1}$ Election outcomes may be treated as exogenous if the identity of the decisive voter is unknown.
} 
Swank (1992), we assume that political parties only aim at achieving economic goals. We ignore electoral policy as a means to partisan policy (Wittman, 1977 and 1983 ) as well as partisan policy as a means to electoral policy. Third, policy makers are not able to commit policy in advance.

\subsection{The Phillips curve}

The economy is described by a simple model of the labour market. Each firm operates in a separate labour market (i) and hires labour up to the point where the real wage is equal to the marginal productivity of labour:

$$
l_{l}^{i}=\sigma_{1}+\zeta_{1} \cdot\left(w_{l}^{i}-p_{l}^{i}\right)+\varepsilon^{i},
$$

where $l_{l}^{i}, w_{l}^{i}$ and $p_{l}^{i}$ are the logs (subscript $l$ ) of employment, the nominal wage and production price in market $i$, respectively. $\varepsilon^{i}$ is a disturbance term with mean zero. Following Blanchard and Fisher (1990), we assume that wages are set by (firm specific) unions, so as to meet an employment target $l_{l}^{* i}$ which is assumed to be a weighted average of employment last period (denoted by subscript -1 ) and the (fixed) labour force in market $i, l_{l}^{s i}$.

$$
l_{l}^{* i}=\omega_{i} \cdot l_{l_{-1}}^{i}+\left(1-\omega_{i}\right) \cdot l_{l}^{s i}, \quad\left(0 \leq \omega_{i} \leq 1\right),
$$

where $\omega_{i}$ is the weight union $i$ gives to the interests of its members. Wages are set before $p_{l}^{i}$ and $\varepsilon^{i}$ are observed. Hence

$$
w_{l}^{i}=E_{-1} p_{l}^{i}+\left(\omega_{i} \cdot l_{l_{-1}}^{i}+\left(1-\omega_{i}\right) \cdot l_{l}^{s i}\right) / \zeta_{1}-\sigma_{1} / \zeta_{1},
$$

where $E_{-1}$ is the expectation operator. Employment results from substituting (3) into (1), yielding

$$
l_{l}^{i}=\zeta_{1} \cdot\left(E_{-1} p_{l}^{i}-p_{l}^{i}\right)+\omega_{i} \cdot l_{l_{-1}}+\left(1-\omega_{i}\right) \cdot l_{l}^{s i}+\varepsilon^{i} .
$$

Finally, by imposing symmetry (which implies that all unions choose the same wage and all firms hire the same number of workers), subtracting both sides of (4) by $l_{l}^{s}$ and taking $u \approx l_{l}^{s}-l_{l}$, we obtain the unemployment equation:

$$
\begin{gathered}
u=\omega \cdot u_{-1}+\zeta_{1} \cdot\left(p_{l}-E_{-1} p_{l}\right)-\varepsilon \\
=\omega \cdot u_{-1}+\zeta_{1} \cdot\left(p-E_{-1} p\right)-\varepsilon,
\end{gathered}
$$

where $p\left(\approx p_{l}-p_{l_{-}}\right)$is the inflation rate. Eq. (5) describes unemployment as a linear function of lagged unemployment and the difference between realised and expected inflation. The dynamics of unemployment should be associated with the weight unions give to their members.

\subsection{The policy maker}

Policy makers' preferences are described by a quadratic loss function in terms of unemployment and inflation.

$$
\mathscr{L}_{i}=\frac{1}{2} \cdot \alpha \cdot\left\{p^{2}+\lambda_{i} \cdot u^{2}\right\}+(1-\alpha) \cdot\left(p-p_{c}\right)^{2},
$$

where $\lambda_{i}$ denotes the weight government $i$ attributes to reducing unemployment. The last term of (6) represents adjustment costs and is discussed below. In this 
paper, we examine a two-party system. The (fixed) political positions of the two parties, party $d$ and $r$, are represented by $\lambda_{d}$ and $\lambda_{r}$, respectively. Both parties differ in their preferences over economic goals. From now on, we assume that party $d$ attributes a higher or equal weight to reducing unemployment than party $r$, $\lambda_{d} \geq \lambda_{r}$. To evade straightforward algebra, we keep the description of the policy problem as simply as possible. For this reason, we assume that governments set prices directly. However, in our model policy makers cannot adjust prices costlessly. More specifically, we assume that the policy maker attaches costs, $\alpha$, to deviations of the inflation rate from the inflation rate prevailing in the absence of policy intervention, $p_{c}$. The weight $\alpha$ expresses the costs of inflation adjustment relative to partisan goals. $\alpha$ is assumed to be equal for party $d$ and $r$. Note that the existence of adjustment costs is not explained by the model, but that adjustment costs are simply assumed. This assumption can be justified in at least two ways. First, policy makers may be reluctant to intervene strongly, because they are uncertain about the effects of inflation on unemployment. Brainard (1967) shows that multiplicative uncertainty usually leads to a conservative use of instruments (see also Gordon 1976; Ghosh and Masson 1991). Swank and Hebbink (1992) report empirical research indicating that multiplicative uncertainty has indeed played a significant role in past US economic policy. ${ }^{2}$ Second, so far, we have treated the government as a decision maker whose goals are directly related to the goals of the governing party. This approach requires that the governing party completely controls the apparatus of the state. The possibility that this requirement is not met cannot be ruled out. Nowadays, bureaucrats are rarely viewed as persons who carry out policies unquestioningly. Moreover, the current sizes of most governments make complete control by politicians virtually impossible. At least, managing the apparatus of the state so that desired policy is carried out involves big efforts and time. The introduction of adjustment costs into the decision problem facing governments may be regarded as a crude way to account for these "administrative" costs.

The policy problem the incumbent party faces is to minimise the expected loss function (6), subject to (5), yielding

$$
p_{i}=\frac{(1-\alpha) \cdot P_{c}-\alpha \cdot \lambda_{i} \cdot \zeta_{1} \cdot\left(\omega \cdot u_{-1}-\zeta_{1} \cdot E_{-1} p\right)}{1+\alpha \cdot \lambda_{i} \cdot \zeta_{1}^{2}}
$$

Eq. (7) describes the optimal strategy of the policy maker, given the strategy of the wage setters (represented by $E_{-1} p$ ).

\subsection{The economic constraints}

Now that we have considered the optimisation problems, facing wage setters and the incumbent party, we can proceed with determining the equilibrium of the model. The equilibrium of the model is defined by the usual Nash conditions that both players select an optimal strategy, given the strategy of the opponent. In a partisan framework, there is a difference between the equilibria of the model in electoral and non-electoral periods.

\footnotetext{
${ }^{2}$ If $\alpha$ is due to multiplicative uncertainty, the assumption that $\alpha$ is equal for party $d$ and $r$ is rather restrictive. Relaxing this assumption, however, will not affect the results derived later essentially.
} 
In non-electoral periods, the political colour of the policy makers is known. Then the equilibrium of the model follows from $p_{i}=E_{-1} p$. Thus (see Eq. (7))

$$
E_{-1} p=(1-\alpha) \cdot p_{c}-\alpha \cdot \lambda_{i} \cdot \zeta_{1} \cdot \omega \cdot u_{-1} .
$$

The voter models to be discussed in the next section revolve around the trade-off between unemployment and inflation. The constraint facing political parties in non-electoral periods, results from substituting (8) into (5):

$$
\begin{aligned}
u & =\zeta_{1} \cdot p+\left(\omega+\alpha \cdot \lambda_{i} \cdot \zeta_{1}^{2} \cdot \omega\right) \cdot u_{-1}-\zeta_{1} \cdot(1-\alpha) \cdot p_{c} \\
& =\zeta_{1} \cdot p+\zeta_{2, i}^{n},
\end{aligned}
$$

where $\zeta_{2, i}^{n}$ represents the part of the constraint facing the policy maker which is independent of (current) economic policy, $p$. Superscript $n$ denotes that $\zeta_{2, i}^{n}$ refers to non-electoral periods. $\zeta_{2, i}^{n}$ depends positively on unemployment last period and the inflation rate prevailing in the absence of policy intervention. From (9) it is easy to see that if $\lambda_{d}>\lambda_{r}$, then $\zeta_{2, d}^{n}>\zeta_{2, r}^{n}$.

Consider now electoral periods. Nominal wages are set before elections are held. Thus uncertainty exists about future policies. In equilibrium, inflation forecasts must be rational:

$$
E_{-1} p=\pi \cdot E_{-1} p_{d}+(1-\pi) \cdot E_{-1} p_{r}
$$

where $E_{-1} p_{d}\left(E_{-1} p_{r}\right)$ is the expected inflation rate under party $d(r)$ and $\pi$ is the probability that party $d$ is elected. Substituting (10) into (5) leads to the following economic constraint:

$$
u=w \cdot u_{-1}+\zeta_{1} \cdot\left(p-\pi \cdot E_{-1} p_{d}-(1-\pi) \cdot E_{-1} p_{r}\right)
$$

To write (11) as a function of $p, u_{-1}$ and $p_{c}$, we must solve (10) and substitute the result into (11). Using (10) and (7) we obtain after tedious, but straightforward, algebra:

$$
\begin{aligned}
u & =\zeta_{1} \cdot p+\eta_{1} \cdot u_{-1}+\eta_{2} \cdot p_{c} \\
& =\zeta_{1} \cdot p+\zeta_{2}^{e},
\end{aligned}
$$

where

$$
\eta_{1}=\omega+\frac{\left[\pi \cdot\left(1+\alpha \cdot \lambda_{r} \cdot \zeta_{1}^{2}\right) \cdot \lambda_{d}+(1-\pi) \cdot\left(1+\alpha \cdot \lambda_{d} \cdot \zeta_{1}^{2}\right) \cdot \lambda_{r}\right] \cdot \alpha \cdot \zeta_{1}^{2} \cdot \omega}{\left(1+\alpha \cdot \lambda_{d} \cdot \zeta_{1}^{2}\right) \cdot\left(1+\alpha \cdot \lambda_{r} \cdot \zeta_{1}^{2}\right)-\left[\pi \cdot\left(1+\alpha \cdot \lambda_{r} \cdot \zeta_{1}^{2}\right) \cdot \lambda_{d}+\left(1-\pi 1+\alpha \cdot \lambda_{d} \cdot \zeta_{1}^{2}\right) \cdot \lambda_{r}\right] \cdot \alpha \cdot \zeta_{1}^{2}}
$$

and

$$
\eta_{2}=\frac{-\zeta_{1} \cdot\left[\pi \cdot\left(1+\alpha \cdot \lambda_{r} \cdot \zeta_{1}^{2}\right)+(1-\pi) \cdot\left(1+\alpha \cdot \lambda_{d} \cdot \zeta_{1}^{2}\right)\right] \cdot(1-\alpha)}{\left(1+\alpha \cdot \lambda_{d} \cdot \zeta_{1}^{2}\right) \cdot\left(1+\alpha \cdot \lambda_{r} \cdot \zeta_{1}^{2}\right)-\left[\pi \cdot\left(1+\alpha \cdot \lambda_{r} \cdot \zeta_{1}^{2}\right) \cdot \lambda_{d}+\left(1-\pi 1+\alpha \cdot \lambda_{d} \cdot \zeta_{1}^{2}\right) \cdot \lambda_{r}\right] \cdot \alpha \cdot \zeta_{1}^{2}}
$$

and superscript $e$ denotes that $\zeta_{2}^{e}$ refers to electoral periods. From (7) it is easy to see that if $\lambda_{d}>\lambda_{r}$ then $p_{d}>p_{r}$. As a consequence, in equilibrium we have $E_{-1} p_{d}>$ $E_{-1} p>E_{-1} p_{r}$. Furthermore, it is straightforward to derive that given $u_{-1}$ and $p_{c}$, $\zeta_{2, d}^{n}>\zeta_{2}^{e}$ and $\zeta_{2, r}^{n}<\zeta_{2}^{e}$. The intuition behind these results is clear. In our model, party $d$ is more inclined to create inflation surprises than party $r$. In non-electoral periods, private agents know the identity of the governing party and respond to its incentives to create inflation surprises. Due to this, inflation expectations depend 
on the identity of the governing party, implying $\zeta_{2, d}^{n}>\zeta_{2, r}^{n}$. In electoral years, private agents do not know the identity of the governing party. Inflation expectations are therefore somewhere between the expected inflation under party $d$ and $r$.

Let us now briefly consider the predictions of this model for unemployment and inflation which follow from minimising (6), subject to (9) for non-electoral periods and (12) for electoral periods. As in Alesina (1987), uncertainty about future policies leads to inflation surprises in electoral periods. Inflation is higher under party $d$ than under party $r$ and consequently unemployment is lower under party $d$ than under party $r$. In non-electoral periods, private agents anticipate upon policy makers' incentives to create inflation surprises. As a result, in non-electoral periods unemployment depends only on past unemployment and the disturbance term, even though inflation is higher under party $d$ than under party $r$.

In this section, we have examined a partisan model of economic policy. We have shown that the trade-off between unemployment and inflation changes over time, due to electoral uncertainty and lagged economic effects. Swank and Hebbink (1992) show that the predictions of this model are consistent with post-war US data. In the next section, we examine how rational voters make their vote decisions in such an environment.

\section{The score and issue model of voter behaviour}

Since Downs' (1957) seminal work, voter behaviour has often been analyzed in a rational choice framework. In a rational choice setting, a voter casts his ballot for the party which, if elected, will offer him the highest expected utility. Like the preferences of political parties, voters' preferences are described by a quadratic function:

$$
V_{v}(p, u)=-\frac{1}{2} \cdot\left\{p^{2}+\lambda_{v} \cdot u^{2}\right\}
$$

where $\lambda_{v}$ is the weight voter $v$ attributes to unemployment. Voter $v$ will cast his ballot for party $d$ rather than for party $r$ if

$$
V_{v}^{d}(\cdot)-V_{v}^{r}(\cdot)=\frac{1}{2} \cdot\left\{\left(p_{r}^{2}-p_{d}^{2}\right)+\lambda_{v} \cdot\left(u_{r}^{2}-u_{d}^{2}\right)\right\}>0
$$

where $V_{v}^{i}, p_{i}$ and $u_{i}$ are the expected values of $V_{v}, p$ and $u$, respectively when party $i$ is the incumbent party.

Now the question arises how do voters determine the expected values of unemployment and inflation under different political parties? In answering this question, two voter models can be distinguished, the score model and the issue model. The issue model, having its roots in the partisan theory, ascribes differences in expected economic outcomes to differences in the objective functions of political parties. In the score model there is agreement between political parties and voters over the economic goals. Instead, the score model highlights differences in the competence of political parties. In Sect. 3.1 and 3.2 we examine the relationships between economic outcomes and the popularity of political parties in the score and issue model, respectively.

\subsection{The score model}

In the score model voters do not see "ideological" differences between political parties. This implies that the policy weight in the loss function of the policy model 
(Eq. (6)) is independent of the political colour of the government $\left(\lambda_{i}=\lambda_{g}\right.$ for all types of governments $i$ ). ${ }^{3}$ Since the preferences of political parties do not differ, no uncertainty exists about future economic policy. As a consequence, Eq. (9) represents the economic constraint facing governments in electoral periods as well as in non-electoral periods. For this reason, we may drop the superscript $n$.

In the score model expected economic outcomes differ under different political parties because some parties are better able to achieve economic goals than other parties. Thus political parties differ in their abilities to achieve economic goals. The competence of political parties may be reflected by $\zeta_{2, i}$ in (9) (see Persson and Tabellini 1990). For example, a competent political party may be particularly able to negotiate with unions, so that unions attribute high weight to the interests of non-members. This would imply a low $\omega$ in Eq. (5) and a low $\zeta_{2, i}$ accordingly. From (6) and (9), it is easy to derive that a more competent government, facing a relative low value of $\zeta_{2, i}$, can achieve lower unemployment with less inflation.

Let us now examine the decision problem facing voters. The above indicates that in the score model, political parties can be distinguished by their competence, i.e. $\zeta_{2, i}$. If voters were assumed to have perfect information, they would simply make their vote decisions on the basis of $\zeta_{2, i}$, since if $\zeta_{2, d}\left\langle\zeta_{2, r}\right.$, then $\left.V_{v}^{d}\right\rangle V_{v}^{r}$ (see Eq. (14)). ${ }^{4}$ Due to this, we can formalise vote decisions in terms of $\zeta_{2, i}$. A voter will cast his ballot for party $d$ if party $d$ is expected to be more competent than party $r$ :

$$
l_{d, r_{t+1}}=\zeta_{2, r_{t+1}}-\zeta_{2, d_{t+1}}>0 \text {. }
$$

Usually it is assumed that voters do not directly observe the competence of different policy makers (see e.g. Rogoff and Sibert 1988; Persson and Tabellini 1990). Instead, voters draw information about the competence of political parties from past economic outcomes. Competence is assumed to be partially lasting. Thus a political party that was able to deal with economic problems in the past is expected to be able to deal with economic problems tomorrow. Because the environment in which political parties operate slowly changes, it is natural to assume that the abilities of political parties in the recent past carry more weight than the abilities of political parties in the long past. This can be formalised by assuming that the expected competence of a political party follows a geometric lag distribution (cf. Fiorina 1981, p 75):

$$
\zeta_{2, i_{t+1}}=\beta_{2} \cdot \sum_{j=0}^{\infty} \beta_{1}^{j} \cdot \zeta_{2, i_{t-j}} \text { with } 0<\beta_{1}<1 \beta_{2}>0
$$

where $t$ is a time index and $\zeta_{2, i_{t-j}}$ reflects the abilities of political party $i$ to deal with economic problems at time $t-j$. Substitution of (16) into (15) for both party $d$ and $r$ leads to

$$
l_{d, r_{t+1}}=\beta_{1} \cdot l_{d, r_{t}}+\beta_{2} \cdot\left[\zeta_{2, r_{t}}-\zeta_{2, d_{t}}\right] .
$$

There remains the determination of $\zeta_{2, d_{t}}$ and $\zeta_{2, r_{t}}$. Suppose that in period $t$ party $d$ is the incumbent party and that party $r$ is the opposition party. As to the

\footnotetext{
${ }^{3}$ This assumption may be the result of a two-party system in which the ultimate goal of political parties is mobilising votes (Mueller 1989, p. 278).

${ }^{4}$ Note that differences in $\zeta_{2, i}^{n}$ are not due to differences in the policy weights of political parties.
} 
determination of $\zeta_{2, d_{t}}$, voters can use current economic outcomes. Voters are assumed to have imperfect information, in the sense that they are not able to discern random changes in economic outcomes from changes in economic outcomes, resulting from shifts in the competence of the incumbent party. $\zeta_{2, d_{t}}$ can be derived from the government model by using (9):

$$
\zeta_{2, d_{t}}=u_{t}-\zeta_{1} \cdot p_{t}
$$

Of course, economic outcomes do not provide information about the competence of the opposition party. Usually, it is assumed that if party $r$ were in office, $\zeta_{2, r_{t}}$ would take its "normal", fixed value, say $\hat{\zeta}_{2}$ :

$$
\zeta_{2, r_{t}}=\hat{\zeta}_{2} \text {. }
$$

Together Eqs. (16) and (19) imply that in the voters' view, the opposition party gradually develops into a party with a "normal record". Substituting (18) and (19) into (17) yields

$$
l_{d, r}=\beta_{1} \cdot l_{d, r_{t-1}}-\beta_{2} \cdot u_{t}+\beta_{2} \cdot \zeta_{1} \cdot p_{t}+\beta_{2} \cdot \hat{\zeta}_{2}
$$

Eq. (25) has served as a starting point for numerous empirical analyses. Sometimes other economic variables were included, in particular growth in national income, but the main hypothesis behind the score model had long been maintained: favourable economic outcomes improve the record of the incumbent party and its popularity accordingly. Considerable evidence exists supporting this hypothesis. For several countries, negative effects of unemployment and inflation on the government's or the president's popularity have been found (for a survey, see Mueller 1989).

\subsection{The issue model}

In this section, we examine the main properties of the issue model. In the issue model, political parties do not differ in their abilities to achieve economic goals, but differ in their preferences over economic goals. In the policy model discussed in the previous section, this implies that political parties attach different costs to unemployment $\left(\lambda_{d}>\lambda_{r}\right.$ in (6)). Now let us see, how in the partisan framework, utility maximising voters make their vote decisions.

Vote decisions are made at the beginning of each period, thus after nominal wages are set. As a consequence, voters take as given the trade-off between unemployment and inflation. In the remaining part of this section, we will simply describe the economic constraint facing political parties by

$$
u=\zeta_{1} \cdot p+\zeta_{2}
$$

but the reader should remember that $\zeta_{2}$ changes over time as expressed by (9) and (12). Given (21), party $d$ is associated with low unemployment and party $r$ is associated with low inflation. In making their vote decisions, voters have to determine whether they are prepared to accept a higher inflation rate for a lower unemployment rate. This is formalised by (14), from which the following property of the issue model can be derived.

Property I: Every voter votes for the party closest to his most preferred position in terms of $p$. 
Proof: First, define $p_{v}$ as the inflation rate most preferred by voter $v . p_{v}$ results from maximising (13) with respect to $p$, subject to (21). By substituting (21) into (13) we get

$$
V_{v}(p)=-\frac{1}{2} \cdot\left(1+\lambda_{v} \cdot \zeta_{1}^{2}\right) \cdot p^{2}-\lambda_{v} \cdot \zeta_{1} \cdot \zeta_{2} \cdot p-\frac{1}{2} \cdot \lambda_{v} \cdot \zeta_{2}^{2},
$$

where $V_{v}\left(p_{v}\right)$ is the absolute maximum. Eq. (22) evaluates alternative policies in terms of $p$. Let us now return to Property I. We can split Property I into two parts:

Property Ia: If $p_{d}-p_{v}>p_{v}-p_{r}$, voter $v$ votes for party $r$.

Property Ib: If $p_{d}-p_{v}<p_{v}-p_{r}$, voter $v$ votes for party $d$.

We can confine ourselves to proving Property Ia as the proof of Property Ib is symmetric. First, consider a situation where $p_{v} \leq p_{r}<p_{d}$. Eq. (22) shows that for $p>p_{v}, V_{v}(\cdot)$ is a strictly decreasing function. Hence if $p_{v} \leq p_{r}<p_{d}$, then $V_{v}\left(p_{r}\right)>$ $V_{v}\left(p_{d}\right)$, so that voter $v$ will vote for party $r$. Now consider a situation where $p_{r}<p_{v}<p_{d}$. Since $V_{v}(p)$ is a symmetric function with an extremum at $p_{v}$, we know that $V_{v}\left(p_{v}+p_{i}\right)=V_{v}\left(p_{v}-p_{i}\right)$. Hence,

$$
V_{v}\left(p_{r}\right)=V_{v}\left(p_{v}-\left(p_{v}-p_{r}\right)\right)=V_{v}\left(p_{v}+p_{v}-p_{r}\right) .
$$

The condition of Property Ia implies that $p_{v}+p_{v}-p_{r}<p_{d}$. Since $\left(p_{v}-p_{r}\right)>0$ and $V_{v}(p)$ is a strictly decreasing function for $p>p_{v}$, we have

$$
V_{v}\left(p_{r}\right)=V_{v}\left(p_{v}+p_{v}-p_{r}\right)>V_{v}\left(p_{d}\right) .
$$

Thus voter $v$ votes for party $r$.

Property I indicates that the issue model and the demand-side of the well-known Hotelling-Downs model are closely related. In the Hotelling--Downs model, political preferences are depicted as lying along a left-right dimension and each voter is assumed to vote for the party closest to his most preferred position.

Let us now examine the relationship between the economic system and vote decisions. In the issue model, both voters and political parties take as given the working of the economy, represented by (21). However, Sect. 2 shows that in the policy model $\zeta_{2}$ changes over time. It is thus of interest to examine the effects of a rise in $\zeta_{2}$ on vote decisions.

Property II: If the distribution of voters' preferences can be represented by a positive valued function, a rise in $\zeta_{2}$ increases the number of votes cast for party $d$.

Proof: The condition of Property II implies that there is at least one voter, let us say voter $m$, who is indifferent between party $d$ and party $r$. For this voter, $V_{m}^{d}(\cdot)-$ $V_{m}^{r}(\cdot)=0$ holds (see Eq. (14)). Hence,

$$
\frac{1}{2} \cdot\left\{\left(p_{r}^{2}-p_{d}^{2}\right)+\lambda_{m} \cdot\left(u_{r}^{2}-u_{d}^{2}\right)\right\}=0 .
$$

Substituting (21) into (25) gives

$$
\lambda_{m} \cdot\left\{\zeta_{1}^{2} \cdot\left(p_{r}^{2}-p_{d}^{2}\right)+2 \cdot \zeta_{1} \zeta_{2} \cdot\left(p_{r}-p_{d}\right)\right\}=p_{d}^{2}-p_{r}^{2} .
$$

Now define the function:

$$
\lambda_{m}\left(p_{d}, p_{r}, p_{c}, \zeta_{2}\right)=\frac{p_{d}^{2}-p_{r}^{2}}{\zeta_{1}^{2} \cdot\left(p_{r}^{2}-p_{d}^{2}\right)+2 \cdot \zeta_{1} \zeta_{2} \cdot\left(p_{r}-p_{d}\right)},
$$


$\lambda_{m}(\cdot)$ describes the preference of the voter who is indifferent to party $d$ and party $r$ as a function of $p_{i}, p_{c}$ and $\zeta_{2}$. Thus (27) identifies the voter being indifferent to party $d$ and $r$ in terms of $p_{i}, p_{c}$ and $\zeta_{2}$. Henceforth we will refer to this function as the IVF (Indifferent Voter Function). From Property I it is easy to see that every voter who attributes a higher (lower) weight to unemployment than voter $m$, votes for party $d$ (party $r$ ). This implies that, the higher $\lambda_{m}(\cdot)$, the more votes party $r$ gets. Obviously, this a very useful property of this function, since it enables us to determine economic influences on election outcomes by examining the properties of $\lambda_{m}(\cdot)$. To prove Property II we have to show that $\partial \lambda_{m} / \partial \zeta_{2}<0$.

First note that $\lambda_{m}(\cdot)$ can be simplified by dividing the numerator and denominator of (27) by $\left(p_{d}-p_{r}\right)$, leading to

$$
\lambda_{m}\left(p_{d}, p_{r}, p_{c}, \zeta_{2}\right)=\frac{p_{d}+p_{r}}{-\zeta_{1}^{2} \cdot\left(p_{r}+p_{d}\right)-2 \cdot \zeta_{1} \cdot \zeta_{2}} .
$$

Next, define

$$
B=-\zeta_{1}^{2} \cdot\left(p_{r}+p_{d}\right)-2 \cdot \zeta_{1} \cdot \zeta_{2}=\frac{1}{2} \cdot\left(u_{r}^{2}-u_{d}^{2}\right) /\left(p_{d}-p_{r}\right)>0 .
$$

Differentiating (28) with respect to $\zeta_{2}$, using $p_{i}=\left[(1-\alpha) \cdot p_{c}-\alpha \cdot \lambda_{i} \cdot \zeta_{1} \cdot \zeta_{2}\right] /$ $\left[1+\alpha \cdot \lambda_{i} \cdot \zeta_{1}^{2}\right]$ gives after some rearrangements:

$$
\frac{\partial \lambda_{m}(\cdot)}{\partial \zeta_{2}}=2 \cdot \zeta_{1}\left\{\frac{(1-\alpha) \cdot p_{c}}{1+\alpha \cdot \zeta_{1}^{2} \cdot \lambda_{d}}+\frac{(1-\alpha) \cdot p_{c}}{1+\alpha \cdot \zeta_{1}^{2} \cdot \lambda_{r}}\right\} / B^{2}<0 .
$$

Before dwelling on the intuition behind Property II, let us first analyze a third property of the issue model. Suppose that after nominal wages are set, $p_{c}$ rises. How does this affect the popularity of political parties?

Property III: An unanticipated increase in the inflation rate prevailing in the absence of policy actions, $p_{c}$, increases the number of votes cast for party $r$.

Proof: To prove Property VI we have to show that $\partial \lambda_{m}(\cdot) / \partial p_{c}>0$.

$$
\frac{\partial \lambda_{m}(\cdot)}{\partial p_{c}}=-2 \cdot \zeta_{1} \cdot \zeta_{2}\left\{\frac{(1-\alpha)}{1+\alpha \cdot \zeta_{1}^{2} \cdot \lambda_{d}}+\frac{(1-\alpha)}{1+\alpha \cdot \zeta_{1}^{2} \cdot \lambda_{r}}\right\} / B^{2}>0 .
$$

The intuition behind Properties I and II is straightforward. The key idea behind the issue model is that different parties are better in different issues. A rise in $\zeta_{2}$ makes unemployment a more manifest problem. Since party $d$ is expected to be better in reducing unemployment than party $r$, party $d$ benefits from a rise in $\zeta_{2}$. In contrast, an unanticipated rise in $p_{c}$ aggravates the inflation problem. Due to this, party $r$ which assigns a high priority to fighting inflation, benefits from a rise in $p_{c}$.

From (9) and (12), we know that a rise in unemployment and $p_{c}$ increases $\zeta_{2}$. Thus high unemployment increases the popularity of party $d$. The effects of an anticipated rise in $p_{c}$ on the popularity of political parties are ambiguous. On the one hand, a rise in $p_{c}$ increases the popularity of party $r$ through (30), but on the other hand it increases the popularity of party $d$ through (9) and (12). In the next section, we will associate the inflation rate, prevailing in the absence of policy, $p_{c}$, with the lagged inflation rate.

In the issue model, the effects of economic conditions on the popularity of political parties are independent of which party is in office. In this respect, the issue model deviates from the score model, according to which the incumbent (opposition) party benefits (suffers) from favourable economic outcomes, irrespective of its political colour. 


\section{Preliminary evidence}

In the previous section, we have seen that the score and issue model have different empirical implications. Roughly, the issue model predicts that the popularity of the republican (democratic) party increases (decreases) when unemployment declines. The effects of inflation on popularity are ambitious, but have different directions for democratic and republican administrations. On the other hand, the score model predicts that the incumbent party, regardless of its political colour, benefits from low inflation and low unemployment. This section reports some simple regressions of approval rates for American presidents that indicate that the predictions of both models are consistent with the data.

Before dwelling on the estimation results, a few remarks are in order. First, the estimates are based on data of presidential popularity ratings from the well-known Gallop Polls rather than on votes, because of the large number of observations which makes discrimination between the two voter models less difficult. The popularity series offers sufficient data to evaluate the models' predictions accurately. It is without saying that approval rates are not equivalent to election outcomes, even though earlier research suggests that both are closely related (Fiorina, 1981). Nevertheless, we assume that the approval rates correspond to voters' party preferences. In the Appendix estimates are reported on the basis of data on presidential elections for the period 1904-1988. In essence, these estimates are in line with the estimates presented below. Second, we confine ourselves to estimating simple linear regressions. However, the issue model suggests that the relationships between economic and election outcomes are more complicated. Thus the regressions can only be regarded as crude approximations of the issue model's predictions. Third, apart from economic variables, the regressions include three political dummy variables. A dummy variable for the Vietnam war, war, is included to reflect the dissatisfaction of the electorate with the involvement of the US in the Vietnam war. In addition, the equations to be estimated include a dummy variable for the Watergate period, water. Finally, a dummy variable, dumdem, is added, taking the value 1 when a democratic president is in office and is 0 otherwise. In the estimated equations, the dummy variables have the right signs and are generally significant at conventional significant levels.

Following McFadden (1974), we make use of a simple logit model. The difference between the logarithms of the proportion of approval for the democratic party $(\operatorname{prop}(d))$ and the republican party $(\operatorname{prop}(r))$ serves as the dependent variable, lpop $=\log [\operatorname{prop}(d) / \operatorname{prop}(r)]$. Since the resultant model is heteroscedastic, the equations are estimated with generalised least squares. The estimation results are presented in Table 1.

The first column of Table 1 shows that the main properties of the score model are consistent with the data. The variables $s u$ and $s p$ refer to unemployment and inflation, respectively. Their values are positive under a democratic administration and negative under a republican administration (for example, $s u=$ dumdem $\cdot u-$ $(1-$ dumdem $) \cdot u)$. As anticipated, the estimates for $s u$ and $s p$ are both negative, indicating that the incumbent party suffers from unemployment and inflation.

The second column of Table 1 reveals that the main predictions of the issue model are also consistent with the data, although the standard errors for $u$ and $p$ are rather high. The estimates suggest that the democratic party benefits from unemployment while the republican party benefits from inflation. Together, the estimates presented in the first two columns of Table 1 suggest that the data cannot forcefully discriminate between the score and issue model. In our opinion, this is 
Table 1. Estimates of popularity functions for the United States, 1964.1-1986.4

\begin{tabular}{lccc}
\hline & Score model & Issue model & Score/issue model \\
\hline$l p o p_{-1}$ & $0.549(0.069)^{* *}$ & $0.716(0.059)^{* *}$ & $0.430(0.069)^{* *}$ \\
$s u$ & $-0.047(0.018)^{* *}$ & - & $0.017(0.056)$ \\
$s p$ & $-0.048(0.012)^{* *}$ & - & $-0.081(0.014)^{* *}$ \\
$u$ & - & $0.034(0.019)^{*}$ & $0.084(0.031)^{* *}$ \\
$p$ & - & $-0.021(0.011)^{*}$ & $-0.052(0.012)^{* *}$ \\
war & $-0.463(0.117)^{* *}$ & $-0.109(0.109)$ & $-0.352(0.161)^{* *}$ \\
water & $0.576(0.114)^{* *}$ & $0.598(0.127)^{* *}$ & $0.739(0.111)^{* *}$ \\
dumdem & $1.356(0.308)^{* *}$ & $0.146(0.069)^{* *}$ & $1.041(0.369)^{* *}$ \\
constant & $-0.691(0.158)^{* *}$ & $-0.189(0.136)$ & $-0.726(0.150)^{* *}$ \\
$R^{2}$ & 0.815 & 0.782 & 0.850 \\
$Q(10)$ & 10.873 & 6.061 & 7.472 \\
$h$ & 0.262 & 0.091 & 0.298 \\
$F(2,83)$ & 9.722 & 18.889 & - \\
\hline
\end{tabular}

Notes: All equations are estimated with generalised least squares. Standard errors are in parentheses. * indicates significant at a 0.10 level and ** indicates significant at a 0.05 level. $R^{2}$ is the coefficient of determination, $Q(10)$ is the $Q$-statistic of Box and Pierce for 10 autocorrelations and $h$ is Durbin's $h$. $F(2,83)$ is used to test the restrictions implied by the score and issue model. For both models the two restrictions are soundly rejected. Source: lpop, Gallop; $u$ and $p$, OECD

not a serious problem, since both models need not to exclude each other. For why should voters ignore the records of political parties in a partisan world?

In the third column of Table 1, the estimates of an unconstrained popularity function are presented. The estimates once again fail to show the superiority of one of the two models: All coefficients appear to be significant at fairly high statistical levels, except for su. Apparently, the score and issue model can coexist. All in all, our findings sketch a nice picture of the American voter. In evaluating political parties, the American voter considers partisan policies and, in addition, punishes (rewards) the incumbent for poor (good) economic performance.

\section{Conclusions}

The main objective of this paper has been to examine a voter model based on the partisan theory. First, we have presented a policy model in which two political parties differ in their preferences over unemployment and inflation. We have demonstrated that this model leads to cycles in economic variables, due to electoral uncertainty. In contrast to Alesina (1987), partisan effects on economic variables are partially lasting due to lagged economic effects.

Next, we have examined how voters make their vote decisions in this partisan setting. We have shown that vote decisions depend on the policy problems, facing political parties. Voters appear to pick the party that best fits the current economic problems. As a result, the political party that ascribes a high priority to reducing unemployment (inflation) benefits from unemployment (inflation). These results conflict with the predictions of conventional voter models, according to which the incumbent party benefits from low unemployment and low inflation, irrespective of its political colour.

Estimates of approval rates for American presidents provide support for both the partisan voter model and the conventional voter model. Apparently, the American voter takes partisan effects on economic variables into consideration as 
Table 2. Estimates of vote functions for the United States, 1904-1988

\begin{tabular}{lccc}
\hline & Score model & Issue model & Score/issue model \\
\hline$s u$ & $0.001(0.010)$ & - & \\
$s p$ & $-0.047(0.013)^{*}$ & - & \\
$u$ & - & $0.034(0.009)^{* *}$ & $0.029(0.009)^{* *}$ \\
$p$ & - & $-0.022(0.011)^{*}$ & $-0.024(0.011)^{* *}$ \\
$M$ & $0.651(0.177)^{* *}$ & $0.295(0.094)^{* *}$ & $-0.012(0.006)^{*}$ \\
dumdem & $-0.346(0.093)^{* *}$ & $-0.348(0.091)$ & $0.572(0.174)^{* *}$ \\
constant & 0.525 & 0.530 & $-0.431(0.098)^{* *}$ \\
$R^{2}$ & 2.250 & 2.294 & 0.601 \\
DW & & & 2.313 \\
\hline
\end{tabular}

Notes: All equations are estimated with generalised least squares. Standard errors are in parentheses. * indicates significant at a 0.10 level and ** indicates significant at a 0.05 level. $R^{2}$ is the coefficient of determination. Source: Fair (1978) OECD and Statistical Abstract of the United States

well as the overall record of political parties. More generally, our findings indicate the need for a voter model that integrates the main elements of the score and issue model. Other points on the research agenda are the extension of our "static" model to a multi-period model and the examination of models in which political party may aim at both electoral and partisan goals.

\section{Appendix}

Table 2 reports estimates of vote functions based on data of presidential elections. As dependent variable serves $\log$ (popp/(1 - popp), where popp is the democratic percentage of the two-party votes for the presidential elections between 1904-1988. The independent variables are based on inflation and unemployment rates in the year of election. As in Sect. 4, we have added a dummy variable, taking the value 1 when a democratic president was in power before the elections and taking the value zero otherwise. The lagged dependent variable is dropped from the equation, as it appeared insignificant at conventional levels of significance.

The first column of Table 2 shows the estimates of a vote function based on the score model. These estimates indicate that voters punish administrations for high inflation, but not for high unemployment. These results conflict with column 1 in Table 1, but are in line with the estimation results of the integrated voter model. The second column of Table 2 indicates that the data on presidential elections is consistent with the issue model. Unemployment increases the number of votes for the democratic candidate, while inflation increases the number of votes for the republican candidate. In the third column of Table 2 the estimates of a vote function are presented in which the score and issue model are integrated. We started with estimating a vote function in which no restrictions were imposed on the parameters of the model. In this case the score model was rejected and the estimates were similar to the estimates presented in column 2 . Next, we define a misery index, $M$, as the sum of $s u$ and $s p$ and replace $s u$ and $s p$ by $M$. In line with the score model, we expect that voters punish administrations for high values of $M$. The estimates of the resulting vote function are presented in the third column of Table 2 and are more or less consistent with the estimates reported in Table 1. We may conclude that the estimates on the basis of data on presidential elections are broadly in line with the estimates on the basis of popularity data. However, we 
would like to emphasize that estimates presented in Table 2 should be considered with great care, since it is based on a very small number of observations.

Acknowledgements. I wish to thank Richard Bugnics and Wilko Letterie for helpful comments.

\section{References}

Alesina A (1987) Macroeconomic policy in a two-party system as a repeated game. Q J Econ 52: $651-678$

Alesina A, Rosenthal H (1989) Partisan cycles in congressional elections and the macroeconomy. Am Pol Sci Rev 83: 371-398

Alesina A, Sachs J (1988) Political parties and the business cycle in the United States, 1948-1984 J Money, Credit Banking 20: 63-82

Balke NS (1991) Partisanship theory, macroeconomic outcomes and endogenous elections. South Econ J 57: 920-935

Beck N (1982) Parties, administrations, and American macroeconomic outcomes. Am Pol Sci Rev 76: 82-93

Blanchard OJ, Summers L (1986) Hysteresis and the European unemployment problem. In: Fisher S (ed.), NBER macroeconomics annual. MIT Press, Cambridge

Blanchard OJ, Fisher S (1990) Lectures on macroeconomics. MIT Press, Cambridge

Brainard WC (1967) Uncertainty and the effectiveness of policy. Am Econ Rev 57: 411-425

Chappell HW, Keech WR (1988) The unemployment consequences of Partisan monetary policy. South Econ J 55: 107-122

Downs A (1957) An economic theory of democracy. Harper and Row, New York

Fair R (1978) The effect of economic events on votes for president. Rev Econ Stat 60: 159-173

Fiorina MP (1981) Retrospective voting in American national elections. Yale University Press, New Haven

Frey BS, Schneider. F (1978) An empirical study of politico-economic interaction in the United States. Rev Econ Stat 60: 172-183

Ghosh A, Masson PR (1991) Model uncertainty, learning, and the gains from coordination. Am Econ Rev 81: 465-480

Gordon R (1976) An interpretation of the costs on the instruments in deterministic linearquadratic control. Int Econ Rev 17: 779-781

Hibbs DA (1977) Political parties and macro-economic policy. Am Pol Sci Rev 71: $1467-1487$

Kramer G (1971) Short-term fluctuations in U.S. voting behaviour, 1896-1964. Am Pol Sci Rev 65: 131-143

McCallum B (1978) The political business cycle: An empirical test. South Econ J 44: 505-515

McFadden D (1974) Conditional logit analysis of qualitative choice behavior. In: Zarembka $P$ (ed.) Frontiers in Econometrics. New York, pp 105-142

Mueller DC (1989) Public choice II. Cambridge University Press, Cambridge

Nordhaus W (1975) The political business cycle. Rev Econ Stud 42: 169-190

Persson T, Tabellini G (1990) Macroeconomic policy, credibility and politics. Harwood Academic Publishers, Chur

Rogoff K, Sibert A (1988) Equilibrium political business cycles. Rev Econ Stud 55: 1-16

Swank OH (1993) A voter model based on the Partisan theory. Public Choice 75: 339-356

Swank OH, Hebbink E (1992) Estimation of preference weights in a model of monetary policy with multiplicative uncertainty. Discussion Paper 9216/P, Erasmus University Rotterdam

Wittman D (1977) Candidates with policy preferences: a dynamic model. J Econ Theory 14: $180-189$

Wittman D (1983) Candidate motivation: a synthesis of alternative theories. Am Pol Sci Rev 77: 143-157 